\title{
Correction to: Exhaled nitric oxide is not a biomarker for idiopathic pulmonary arterial hypertension or for treatment efficacy
}

Majid Malekmohammad', Gert Folkerts², Babak Sharif Kashani ${ }^{3}$, Parisa Adimi Naghan ${ }^{3}$, Zahra Habibi Dastenae ${ }^{1}$ Batoul Khoundabi ${ }^{4}$, Johan Garssen ${ }^{2}$, Esmaeil Mortaz ${ }^{5 *}$ and lan M. Adcock ${ }^{6,7}$

\section{Correction to: BMC Pulm Med http://dx.doi.org/10.1186/s12890-019-0954-z}

Following publication of the original article [1], the authors flagged that the name of the author 'Batoul Khoundabi' had been provided with an incorrect spelling: 'Batoutl' was given in place of 'Batoul'.

This typo has now been corrected in the original article and the corrected version is provided with this correction.

\footnotetext{
Author details

${ }^{1}$ Tracheal Disease Research Center, National Research Institute of Tuberculosis and Lung Diseases (NRITLD), Shahid Beheshti University of Medical Sciences, Tehran, Iran. ${ }^{2}$ Division of Pharmacology, Utrecht Institute for Pharmaceutical Sciences, Faculty of Science, Utrecht University, Utrecht, Netherlands. ${ }^{3}$ Chronic Respiratory Diseases Research Center, National Research Institute of Tuberculosis and Lung Diseases (NRITLD), Shahid Beheshti University of Medical Sciences, Tehran, Iran. ${ }^{4}$ Helal-e-Iran Applied Science Higher Education Institute Red crescents society of Iran, Tehran, Iran. ${ }^{5}$ Clinical Tuberculosis and Epidemiology Research Center, National Research Institute of Tuberculosis and Lung Diseases (NRITLD), Shahid Beheshti University of Medical Sciences, Tehran, Iran. ${ }^{6} \mathrm{Cell}$ and Molecular Biology Group, Airways Disease Section, Faculty of Medicine, National Heart and Lung Institute, Imperial College London, London, UK. PPriority Research Centre for Asthma and Respiratory Disease, Hunter Medical Research Institute, University of Newcastle, Newcastle, NSW, Australia.
}

Published online: 05 November 2019

\section{Reference}

1. Malekmohammad, et al. Exhaled nitric oxide is not a biomarker for idiopathic pulmonary arterial hypertension or for treatment efficacy. BMC Pulm Med. 2019;19:188. https://doi.org/10.1186/s12890-019-0954-z.

The original article can be found online at https://doi.org/10.1186/s12890019-0954-z

* Correspondence: emortaz@gmail.com

${ }^{5}$ Clinical Tuberculosis and Epidemiology Research Center, National Research Institute of Tuberculosis and Lung Diseases (NRITLD), Shahid Beheshti University of Medical Sciences, Tehran, Iran

Full list of author information is available at the end of the article

(c) The Author(s). 2019 Open Access This article is distributed under the terms of the Creative Commons Attribution 4.0 International License (http://creativecommons.org/licenses/by/4.0/), which permits unrestricted use, distribution, and reproduction in any medium, provided you give appropriate credit to the original author(s) and the source, provide a link to the Creative Commons license, and indicate if changes were made. The Creative Commons Public Domain Dedication waiver (http://creativecommons.org/publicdomain/zero/1.0/) applies to the data made available in this article, unless otherwise stated. 